\title{
The effect of a repeat septic shock simulation on the knowledge and skill performance of undergraduate nursing students
}

\author{
Mary Beth R. Maguire*1, Anne White ${ }^{1}$, Jane D. Brannan ${ }^{1}$, Austin R. Brown ${ }^{2}$ \\ ${ }^{1}$ WellStar School of Nursing, Kennesaw State University, United States \\ ${ }^{2}$ Department of Statistics and Analytical Sciences, Kennesaw State University, United States
}

Received: July 8, 2020

Accepted: September 2, $2020 \quad$ Online Published: September 14, 2020

DOI: $10.5430 /$ jnep.v11n1p30

URL: https://doi.org/10.5430/jnep.v11n1p30

\begin{abstract}
Background: Prelicensure nursing students possess minimal knowledge and skill to implement sepsis protocols effectively. This article evaluates an educational project to assess the impact of a repeat septic shock simulation on pre-licensure nursing students' knowledge and skill competency.

Methods: A quasi-experimental, repeated measures, pre-post design strategy was used to evaluate a repeat septic shock simulation. A convenience sample of one-hundred-forty-three $(\mathrm{N}=143)$ senior baccalaureate nursing students enrolled in the study. The project consisted of a septic shock didactic session, septic shock simulation with a high-fidelity mannequin, debrief, repeat simulation followed by a second debrief as a component of a complex health nursing course. Ninety-seven $(n=97)$ participants were randomly assigned to groups of up to five students to participate in a repeat septic shock simulation. Forty-six ( $\mathrm{n}=46)$ participants were randomly assigned to up to five students and served as a control group. The control group participated in all study elements except the repeat simulation.

Results: The percent change in nursing students' knowledge scores from Pre-simulation to Post-simulation was statistically significant $(p<.001)$. The initial and repeat simulation realized modest gains in competency scores between the initial and repeated simulation.

Conclusions: Providing concurrent experiences using a screening tool in real-time while simultaneously providing an opportunity to practice and refine clinical judgment through a repeat simulation proved effective.
\end{abstract}

Key Words: Sepsis, Simulation, Repeat, Nursing student, Knowledge, Skill Performance

\section{INTRODUCTION}

One commonly occurring, yet often missed, patient scenario in health care is the rapidly deteriorating septic shock patient. It is the leading cause of critical illness and hospital mortality, resulting in nearly 270,000 American deaths per year. ${ }^{[1]}$ Sepsis requires rapid recognition and action to avoid adverse patient outcomes. New evidence-based guidelines for sepsis management, developed by the Surviving Sepsis Campaign (SSC), lend hope of a comprehensive approach to early recognition and treatment. ${ }^{[2-5]}$

Nurses positioned as front-line care providers are responsible for detecting and responding to early signs of sepsis. Several tools and protocols are available to assist with the identification of impending sepsis, such as the quick Sequen-

\footnotetext{
*Correspondence: Mary Beth R. Maguire; Email: mmaguir5@kennesaw.edu; Address: WellStar School of Nursing, Kennesaw State University, United States.
} 
tial (Sepsis-related) Organ Failure Assessment (qSOFA). ${ }^{[4-8]}$ However, studies indicate there are many barriers to nurses' recognition and response to early signs of clinical deterioration in patients. ${ }^{[9,10]}$ One barrier identified is a lack of clinical knowledge regarding sepsis. Nurses must receive training on early detection and management to improve patient outcomes. ${ }^{[11]}$ To that end, it is incumbent for educators to incorporate this critical knowledge into pre-licensure nursing education, and provide opportunities for skill application in a simulated, safe and realistic environment.

In 2010, Benner ${ }^{[12]}$ and colleagues challenged nurse educators to transition from teaching students how to think critically to teaching students how to clinically reason. Clinical reasoning remains a relevant issue to address in nursing education today. Critical thinking uses a cognitive process, not dependent on the situation, but only on the knowledge the nurse possesses. In contrast, clinical reasoning involves both cognitive and metacognitive processes. Metacognition processes the evidence and knowledge as it applies to a patient to discern necessary action. Therefore, clinical reasoning is the application of critical thinking to a clinical situation and requires reflection. Knowing the patient, grasping baseline data, and understanding the patient's response to the situation at hand is effective clinical reasoning. ${ }^{[13]}$ If nursing education aims to socialize graduates into the professional role of nurses ${ }^{[12]}$ then methods are needed to encourage students to reflect critically. A repetitive simulation experience is a teaching method to be considered.

Emerging evidence suggests that simulation-based education's efficiency is related to the frequency of simulation exposure ${ }^{[14-19]}$ and increased opportunities for reflection. ${ }^{[20,21]}$ However, there is a gap in research exploring the use of repetitive simulation exposures and reflection with pre-licensure students' sepsis specific knowledge and skill. This article evaluates the use of a repeat simulation learning strategy in developing undergraduate nursing students' knowledge and skills in caring for patients in septic shock.

\subsection{Aim and research question}

This study aimed to explore the impact of a repeat simulation depicting a patient experiencing septic shock on pre-licensure nursing students' knowledge and skills.

The research questions were: 1) Is there a change in students' knowledge regarding the management of a simulated patient in septic shock after a structured faculty-led debrief and an immediate repeat of the scenario? 2) Is there a change in students' skills regarding the management of a simulated patient in septic shock after a structured faculty-led debrief and an immediate repeat of the scenario?

Published by Sciedu Press

\subsection{Background}

The depth and breadth of knowledge required of nurses entering the health care practice today has dramatically increased over the last decade. ${ }^{[2]}$ There is limited time available for pre-licensure nursing students to assimilate knowledge, apply skills, hone capabilities to recognize critical signs, and critically think. ${ }^{[12]}$ However, these proficiencies are essential for patient safety. As novice practitioners, undergraduate nursing students may miss significant cues and signs in a deteriorating patient, such as septic shock, which begins a cascade of detrimental events. Early recognition, situational awareness of sudden patient deterioration, and timely clinical response are critical to patients' outcomes. The use of clinical simulation in nursing education is a valid and effective pedagogical approach to teaching and learning. ${ }^{[23]}$ Benner ${ }^{[12]}$ noted it is repeated experiences that lead novice students to the ability to clinically reason.

\subsubsection{Acute deterioration}

In clinical reasoning, an essential skill is the ability to recognize and manage a deteriorating patient early. Many investigators have demonstrated that student nurses are inadequately prepared to identify and manage a patient whose condition is deteriorating in the clinical setting. ${ }^{[15,24-28]}$ Students' knowledge or ability to identify physiological causes for patient deterioration increased using simulation, ${ }^{[24,28-31]}$ but as the condition of the patient worsened, the student's skill performance worsened. ${ }^{[24]}$ Several studies found a non-significant correlation between students' knowledge and their ability to improve their scenario performance. ${ }^{[24,27,28,30]}$ However, repetitive practice improves performance. ${ }^{[15,27,30,31,33]}$

Nursing curricula may address the theoretical component of patient deterioration. In many prelicensure nursing programs, students do not have the opportunity to care for a rapidly deteriorating patient or unanticipated patient events. Undergraduate nursing programs have embraced the high-fidelity simulated learning environment as an effective strategy to safely practice high-risk events such as a rapidly deteriorating patient. ${ }^{[36]}$

\subsubsection{Nurses and sepsis}

Patients with sepsis experience a life-threatening systematic inflammatory response caused by a dysregulated response to infection, deemed a medical emergency. ${ }^{[2,5,6]}$ Nurses play a critical role through the urgent assessment, early identification, and goal-directed therapy needed for better patient outcomes. ${ }^{[3,7,11,35]}$

Many different approaches are available to assist nurses, such as clinical decision support systems, ${ }^{[36,37]}$ screening tools, ${ }^{[38-40]}$ and sepsis care bundles. ${ }^{[4,7]}$ However, barriers to early recognition and treatment of a patient experiencing 
sepsis still exist. ${ }^{[9,10,38,41]}$ Bedside nurses need knowledge and practice in early sepsis recognition and treatment. ${ }^{[42]}$ It is essential to provide both practicing nurses and pre-licensure nurses opportunities to develop and refine recognition and response skills in a safe environment without risk to patients.

\subsubsection{Student nurses and sepsis}

The evidence base concerning nursing students' skills in managing patients with sepsis is limited. One study increased content on sepsis in an associate degree in nursing (ADN) program by incorporating a lecture and a simulation scenario on sepsis and early intervention that resulted in improved scores for both knowledge and confidence. ${ }^{[43]}$ Diaz et al. ${ }^{[44]}$ reported on the modification of a pediatric checklist tool to evaluate nursing students' competency during a simulated pediatric sepsis scenario. Assessment and deterioration emerged as the two factors key to improving early recognition of pediatric sepsis. Assessment included recognition of baseline vital signs and timely medication administration. The concept of deterioration contained items regarding the interpretation of changes in baseline vital signs that require action. McCallum et al. ${ }^{[45]}$ proposed early warning systems embedded into electronic medical records to alert deteriorating patient conditions as helpful tools for nurses. These same systems, however, may reduce nursing students' development of clinical decision-making skills resulting from their reliance upon the auto-generated score rather than their assessment.

\subsubsection{Repeat/Repetition simulation}

Several studies focused on repetitive practice with experienced professionals and undergraduate students. Abe et al. ${ }^{[14]}$ studied nurses' perceptions of competence after exposure to four different critical care scenarios during one session. Results indicated improved competence and confidence among nurses functioning as team members. Pediatric residents participated in a study to determine whether repeated exposure to one simulation scenario would translate to improved medical decision making in other scenarios. Results indicated that there was no transfer of decision-making capability. ${ }^{[19]}$ Scoresby and Shelton ${ }^{[20]}$ studied undergraduate college students' learning using 3D simulation to re-do their actions by focusing on the point of error. Results indicated that students used metacognition and reflection in varying degrees as a scaffolding mechanism to identify their failure and avoid making the same mistakes.

Few studies using repetitive practice with nursing students are in the literature. Choi \& $\mathrm{Kim}^{[16]}$ found that nursing students' performance scores improved regardless of role assigned with repeated simulation exposures of emergency care. Kaddoura ${ }^{[17]}$ explored the use of seven different sce- narios with first-year nursing students who had no previous exposure to simulation or assigned clinical. The students' perceived the repeated exposures as useful in developing critical thinking, competence, confidence, and knowledge. A few students viewed the experience as challenging and overwhelming. Bogossian et al. ${ }^{[15]}$ studied undergraduate nursing students who viewed three clinical scenarios with deteriorating patients. The researchers found that students had difficulty recognizing (situational awareness), responding (clinical performance), and functioning on a team during a patient deterioration. The researchers recommended more knowledge and rehearsal of first response strategies. Sivertsen et al. ${ }^{[18]}$ observed that nursing students' perspectives of an unstaffed re-do station provided enhanced learning opportunities, but students preferred to have similar fidelity levels as the original simulation. Sapiano et al. ${ }^{[27]}$ described that nursing students improved knowledge after participating in three virtual scenarios (cardiac, shock, and respiratory) of a deteriorating patient. Performance scores varied between the three scenarios; however, performance scores were higher in the last scenario, possibly indicating that repetitive practice improves performance.

To date, no studies have explored the impact of repetitive practice in a septic shock simulation with pre-licensure students. A gap in knowledge exists between repeated septic shock simulation on the knowledge and skills of undergraduate nurses. This study fills a unique void of a complete repetitive simulation with associated debrief to impact metacognition and improve clinical reasoning/practice.

\subsection{Theory}

Mezirow's ${ }^{[46]}$ Transformative Learning Theory served as the theoretical framework of the research design due to the cyclical/interconnected process of the theory and the dynamic learning opportunity of a repeated septic shock simulation (see Figure 1).

Mezirow $^{[47]}$ postulated authentic learning occurs when individuals faced with a disconcerting event (disorientating dilemma), critically self-examine the previous frame of reference about the experience, and explore other plans of action. ${ }^{[48]}$

The transformative learning theory's primary constructs include the disorienting dilemma, examining assumptions, acquiring new knowledge, and seeking new experiences. Figure 1 demonstrates the theoretical constructs of the research design. The first septic shock scenario provided the disorienting dilemma. Faculty-led debriefing sessions provided an opportunity to examine assumptions. New knowledge was gained through the didactic lecture and demonstrated through 
pre and post-simulation knowledge assessments related to managing a patient in septic shock. Finally, the repeat simulation and associated debrief provided a new experience to address and adapt to the disorienting dilemma.

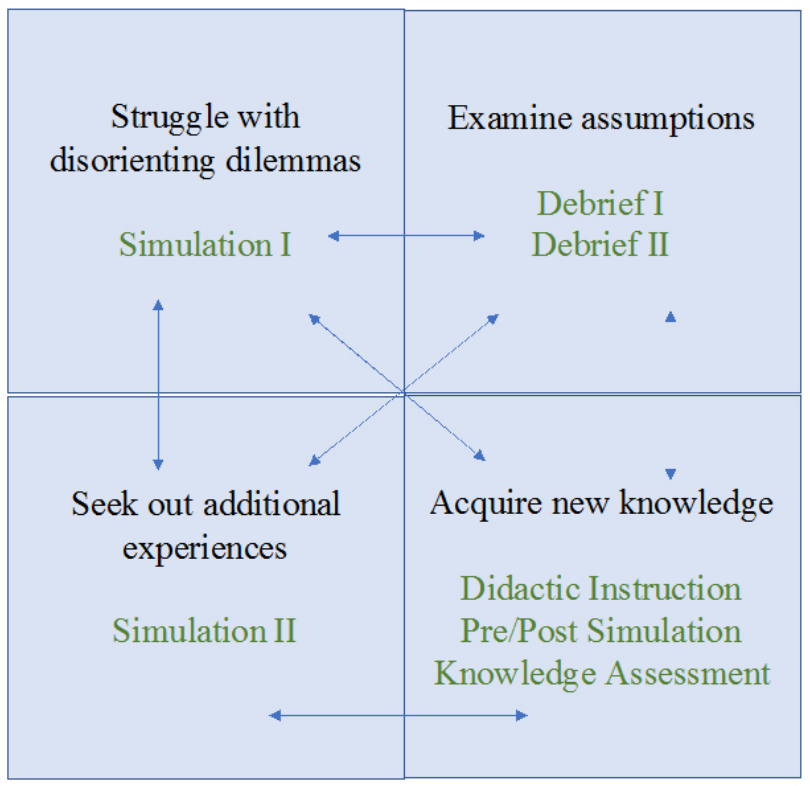

Key: Theoretical constructs Research elements

Figure 1. Research design utilizing transformative learning theory

\section{MeTHODS}

\subsection{Project design}

This study's aim determined the effectiveness of two different educational methods on students' knowledge and skill of caring for a patient in septic shock. Inclusion criteria were students enrolled in an adult health nursing course over three consecutive semesters. The traditional simulation group served as the control. The experimental group received the repeated simulation. A quasi-experimental, twogroup, repeated measures, pretest/posttest design strategy, was used. Both groups received 2-hours of didactic content in the classroom on sepsis and septic shock before the simulation experience.

The control group involved small groups of four or five students immersed in a realistic simulation of a patient in septic shock. The simulation design used the standards of best practice from the International Nursing Association for Clinical Simulation in Nursing. ${ }^{[49]}$ The simulation used a high-fidelity manikin and other life-like equipment to emulate a real-world experience. Standardized, scripted protocols were enacted for the pre-brief, simulation scenario, and debrief sessions. The simulation required students' active engagement and was immediately followed by a structured debrief session.
The experimental group experienced the same simulation as the control group. However, student participants assigned to the experimental group, returned to the simulation suite to repeat the same septic shock scenario for a second time. Participants acted in the same group and roles as previously assigned in the first scenario. Upon the conclusion of the second scenario, a brief bedside faculty-led debrief occurred to reflect on the repeated scenario-specific performance and observations.

\subsection{Ethical considerations}

Before enrolling participants, researchers received Institutional Review Board approval. All students enrolled in the courses participated in the simulations as a course requirement. However, data analysis only occurred from those who consented to the study. Lack of participation in the study had no bearing on students' grades or progression through the nursing program. Performance videos were available only to the research team, who coded the recordings to protect participant confidentiality. Pre/post knowledge questionnaires were de-identified by using a unique code for each participant.

\subsection{Measurement instruments}

Two instruments used in this study were: (1) the Sepsis Shock Questionnaire (SSQ) to measure the level of cognitive skills; and, (2) the Creighton Competency Evaluation Instrument $(\mathrm{C}-\mathrm{CEI} \cap)^{[50]}$ to determine students' skills related to nursing management of septic shock. The SSQ instrument was administered online in a proctored computer lab before any classroom content on sepsis and immediately after the simulation debrief (control group) or after the final repeat simulation debrief (experimental group). The C-CEI $\AA$ instrument was used by researchers to evaluate all video recordings of students' performance during simulations (initial and repeated simulation runs). Each performance was viewed concurrently and discussed by the two researchers in realtime. This ensured faculty consensus on the achievement of minimum expectations of student performance for each competency of C-CEI $\AA$ scoring. Demographic data collected from class enrollment statistics from the three cohorts provided data on age and gender.

The SSQ was used to measure students' level of early recognition and response in the nursing management of septic shock. The instrument was investigator-developed, and the questions were created from the current guidelines for nursing management, as outlined in the Surviving Sepsis Campaign. ${ }^{[7]}$ The SSQ is a 12-item multiple-choice questionnaire addressing the signs and symptoms, diagnostic indicators, importance of early treatment, and nursing management of septic shock. 
Scores range from 0 to 12 ; the higher the score, the higher level of knowledge in caring for a septic shock patient. Four expert educator raters determined content validity. Expertise defined as five or more years of acute care nursing experience and ten or more years of teaching advanced nursing topics at the baccalaureate level or higher. The SSQ had a scale content validity average of 0.94 . There is no reliability of this instrument.

The C-CEI $\left(\right.$ was developed by Todd et al. ${ }^{[50]}$ to measure clinical learning effectiveness in simulation environments. The instrument contains 23 items divided into four domains of general nursing behaviors: assessment, communication, clinical judgment, and patient safety. The C-CEI $\AA$ uses a scale with the following options: 0 (does not demonstrate competency); 1 (demonstrates competency); and N/A (Not applicable) is also available for elements not included in the simulation. Each domain consists of a series of statements. For instance, the assessment domain contains the following: "Obtains Pertinent Data", "Performs Follow-up Assessments as Needed", and "Assesses the Environment in an Orderly Manner".

The C-CEI $\AA$ provides a holistic approach to scoring, allowing the evaluator to observe multiple behaviors in a simulation and rate the performance as a whole. Scores designate students' performance within each domain and as a total score. Scores range from 0 to 46 , with higher scores indicating a higher level of skill performance. Researchers received authorization from the instrument authors to utilize the $\mathrm{C}$ $\mathrm{CEI} \cap$ for the study. The researchers received training from the instrument author guidelines to ensure the reliability of scoring. The instrument has a reported interrater reliability ranging from 0.84 . to $0.89 .{ }^{[50]}$

\subsection{Description of educational interventions}

\subsubsection{Preparation pre-simulation}

One week prior to the simulation sessions, all participants received two-hours of didactic information during the usual class time in the adult health nursing course. The presentation included content on infections and sepsis, including early signs/symptoms of sepsis, evidenced-based recommendations for treatment, and utilization of the qSOFA. The students had no clinical experience as a part of this course.

\subsubsection{Septic simulation}

The early recognition simulation scenario of a patient in septic shock used an adult high-fidelity manikin in the university's simulation laboratory. All faculty (including the researchers) are experienced and trained in simulation and the art of debriefing. The International Nursing Association for Clinical Simulation and Learning best practice standards ${ }^{[49]}$ were used to create the simulation. The objectives of the scenario were to (1) complete a focused assessment; (2) interpret and prioritize findings from assessment utilizing the qSOFA; (3) implement evidence-based interventions (sepsis bundle) in response to patient status ensuring patient safety; and (4) demonstrate professional communication between the nursing team, physician, or emergency response using Introduction, Situation, Background, Assessment, Recommendation, Readback (ISBARR) format.

The students were divided into groups of four or five and randomly assigned participant roles (three active participants and one or two active observers). The roles included "Primary Nurse", "Medication Nurse", "Documentation Nurse", and "Observer". The observers recorded notes about the team performance to share during debrief. The student teams participated in a twenty-minute simulated scenario of a patient in septic shock. The team performance was video recorded.

Immediately following the scenario, a short in-room environmental debrief of up to five minutes occurred to review the scenario's technical details. Then, participants proceeded to a debrief room and engaged in a 20-minute faculty-led debrief. The faculty utilized a pre-developed debrief guide to facilitate reflection and attempt to standardize the experience for participants. Video playback of the scenario was available during debrief if the facilitator deemed the recording necessary to review with participants.

\subsubsection{Control group}

Students who participated in the control group received the preparation pre-simulation activities. The participants also participated in the septic simulation scenario as described above.

\subsubsection{Experimental group}

Students who participated in the experimental group received the identical preparation, pre-simulation, and septic simulation scenario as the control group. However, the experimental group moved back to the simulation lab immediately following debrief, where they acted in the same roles and repeated the 20-minute septic shock scenario. Upon conclusion of the scenario, the faculty led a ten-minute bedside debrief to discuss the scenario specific performance and observations witnessed by the student observers. Consequently, each student had the opportunity to participate in the same simulation twice.

\subsection{Data analysis}

Data were analyzed using two sets of statistical methods to answer the research questions specific to the knowledge and competency assessments. The researchers used the Statistical package $\mathrm{R}^{[51]}$ to provide descriptive and inferential 
statistics. The MIXED procedure in SAS ${ }^{[52]}$ was used to analyze knowledge scores of groups. Knowledge scores between groups used a repeated measures analysis of variance (RMANOVA). A $p$-value of $<.05$ was considered statistically significant. Three t-tests, one paired test, and two independent tests compared the pre and post-treatment scores and the pre and post-treatment scores to the control group scores.

\section{Results}

\subsection{Sample}

A total of 183 students enrolled in the course. One hundred forty-three students $(78 \%)$ consented to participate in the study. The experimental group $(n=97)$ were enrolled in the course during the first two semesters of the year and the control group $(n=46)$ during the third semester. Participants' ages ranged from $21-52$ years $(\mathrm{M}=25.6, \mathrm{SD}=5.8)$ with $86 \%(\mathrm{n}=123)$ who identified as female and $14 \%(\mathrm{n}=20)$ who identified as male.

\subsection{Knowledge assessment}

Concerning research question one: Is there a change in students' knowledge regarding the management of a simulated patient in septic shock after a structured faculty-led debrief and an immediate repeat of the scenario? The total number of correct responses the students gave on their assessment served as the outcome variable.

The results shown in Table 1 indicate that while the observed interaction effect was not statistically significant, the difference between the pretest scores $(\mathrm{M}=5.67, \mathrm{SD}=2.03)$ and the posttest scores $(\mathrm{M}=8.44, \mathrm{SD}=1.98)$ was statistically significant. Additionally, Table 1 suggests that, at the 0.05 level, a significant difference was observed between the treatment group $(\mathrm{M}=6.84, \mathrm{SD}=2.58)$ and the control group ( $\mathrm{M}$ $=7.50, \mathrm{SD}=2.05)$.
Table 1. RM-ANOVA table comparing knowledge score across time and treatment group

\begin{tabular}{lll}
\hline Effect & F-Statistic & $\boldsymbol{p}$-value \\
\hline Treatment Group Effect & 4.92 & .0281 \\
Time Point Effect & 175.57 & $<.0001$ \\
Treatment*Time Interaction Effect & 0.79 & .3759 \\
\hline
\end{tabular}

\subsection{Competency assessment}

Regarding research question two: Is there a change in students' skills regarding the management of a simulated patient in septic shock after a structured faculty-led debrief and an immediate repeat of the scenario? The CCEI $R$ instrument was used by two expert evaluators who watched video recordings of student groups in the simulation. Two nursing faculty researchers evaluated the video recordings who had undergone instrument training provided by the CCEI $R$ instrument authors. Each performance was viewed concurrently and discussed by the researchers in real-time to reach an agreement on CCEI $®$ scoring to determine whether the group demonstrated competency or not in a particular domain. Note, two items, "Interprets Lab Results" and "Documents Clearly, Concisely, and Accurately" were omitted as these elements were not within the scope of the exercise.

The total number of items in which the student group demonstrated competency served as the outcome variable. The research design of the study's competency aspect slightly differed from the knowledge aspect in that the control group performed the simulation once while the treatment group performed the simulation twice. Using three $t$-tests, one paired test and two independent tests, Table 2 shows the comparison of the pre and post-treatment scores, and the pre and post-treatment scores to the control group scores (see Table 2).

Table 2. C-CEI domain score comparison between control and treatment group

\begin{tabular}{|c|c|c|c|c|c|c|c|c|c|c|c|c|c|c|c|}
\hline \multicolumn{4}{|c|}{ Assessment } & \multicolumn{4}{|c|}{ Communication } & \multicolumn{4}{|c|}{ Clinical Judgment } & \multicolumn{4}{|c|}{ Patient Safety } \\
\hline \multicolumn{2}{|c|}{$\begin{array}{l}1^{\text {st }} \\
\text { Simulation }\end{array}$} & \multicolumn{2}{|c|}{$\begin{array}{l}2^{\text {nd }} \\
\text { Simulation }\end{array}$} & \multicolumn{2}{|c|}{$\begin{array}{l}1^{\text {st }} \\
\text { Simulation }\end{array}$} & \multicolumn{2}{|c|}{$\begin{array}{l}2^{\text {nd }} \\
\text { Simulation }\end{array}$} & \multicolumn{2}{|c|}{$\begin{array}{l}1^{\text {st }} \\
\text { Simulation }\end{array}$} & \multicolumn{2}{|c|}{$\begin{array}{l}2^{\text {nd }} \\
\text { Simulation }\end{array}$} & \multicolumn{2}{|c|}{$\begin{array}{l}1^{\text {st }} \\
\text { Simulation }\end{array}$} & \multicolumn{2}{|c|}{$\begin{array}{l}2^{\text {nd }} \\
\text { Simulation }\end{array}$} \\
\hline Mean & SD & Mean & SD & Mean & SD & Mean & SD & Mean & SD & Mean & SD & Mean & SD & Mean & SD \\
\hline 2.86 & 0.38 & -- & -- & 2.86 & 0.90 & -- & -- & 3.43 & 0.98 & -- & -- & 1.77 & 0.79 & -- & -- \\
\hline 2.69 & 0.79 & 2.63 & 0.89 & 2.88 & 0.96 & 3.19 & 0.75 & 4.75 & 1.53 & 4.56 & 1.86 & 2.13 & 1.82 & 2.50 & 1.75 \\
\hline
\end{tabular}

First, when comparing the pre $(\mathrm{M}=12.44, \mathrm{SD}=3.98)$ and post $(\mathrm{M}=12.88, \mathrm{SD}=4.26)$ total treatment scores, no significant difference between the mean scores was observed $(t(15)$ $=0.27, p=.79)$. Comparing the post treatment and control group $(\mathrm{M}=10.71, \mathrm{SD}=2.43)$ scores, while a greater absolute difference between the mean scores, this difference was not statistically significant $(t(19)=1.54, p=.14)$. Clearly, since a significant difference was not observed between the post treatment and control group, it was not observed between the pretreatment and control group either $(t(18)=1.27, p=.22)$.

\section{Discussion}

\subsection{Knowledge findings}

A statistically significant difference between pre and post knowledge scores suggests the didactic and simulation effectiveness as cooperative teaching strategies. The difference in 
knowledge of sepsis gained by didactic instruction or simulation alone is unclear due to assessments obtained after the combined interventions. Previous studies ${ }^{[20,43]}$ support both didactic instruction and simulation as an effective strategy to support metacognition.

There was a statistically significant difference observed in knowledge scores between those who participated in a repeat simulation and those who did not. This finding suggests a repeat simulation is an effective teaching strategy to improve student knowledge of managing a patient in septic shock. These study results are similar to other studies that support repetitive practice. ${ }^{[14,16,27]}$

\subsection{Competency findings}

An overall improvement in mean performance scores for the treatment group was recognized. Specifically, the treatment group had performance gains in the Communication and Safety C-CEI $(R)$ domains. The gains in both of these domains suggest that participants could relay the clinical signs and symptoms of a deteriorating patient and safely manage them. One possible reason for modest improvement in competency scores is the integration of the sepsis screening tool (qSOFA). The ability to implement the qSOFA and communicate the score are the first steps in recognizing and responding to the medical crisis to improve patient survival. Additionally, the repeat simulation improvement in the Safety domain suggests that participants effectively administered the necessary treatment. These findings support previous studies ${ }^{[38-40]}$ focusing on nurses effectively using screening tools to improve early recognition of sepsis.

There were no improvements in scores related to Assessment and Clinical Judgment domains. Researchers noted no systematic assessment in the repeat simulation. Failure to assess may be because the students knew how the scenario would unfold and skipped essential assessment skills to move to the intervention phase quickly. This finding suggests that modification of the second scenario to decrease student familiarity may overcome this deficiency. One repeatedly observed delay in treatment was the inability to correctly initiate intravenous fluid resuscitation, which decreased scores in the Clinical Judgment domain. Failure to initiate proper nursing interventions supports evidence that the inability to intervene appropriately resulted in poor outcomes. ${ }^{[9,10,41]}$ Increased time in psychomotor skill rehearsal may resolve this shortcoming.

Although there was no statistical difference in the repeat simulation performance, there were modest improvements. These modest improvements are worthwhile particularly in the novice phase of one's nursing practice when a student may not have the opportunity in the clinical setting to actively participate in the care of a rapidly deteriorating patient. This study supports the repeat simulation as an effective strategy to provide opportunities to improve performance by clinically reasoning in real-time. Benner ${ }^{[12]}$ recommends such experience to move participants along the continuum of novice to expert clinicians.

\subsection{Limitations}

Several limitations of the study must be recognized. It is significant to highlight researchers used mean aggregate knowledge scores from individual students, yet due to time constraints, competency scores were a three-person team performance. If given the opportunity to work independently, students may have demonstrated greater competency without influencing others. There was also a small sample size, which limited the ability to obtain statistical significance. Additionally, the study used one school of nursing. Replication of the study with other schools could provide greater insight into the effectiveness of a repeat septic shock simulation. Multiple exposures beyond one repeat simulation are necessary to achieve proficiency related to the care of a patient experiencing septic shock. Additionally, longitudinal data is necessary to determine the enduring effect of the treatment.

\section{Conclusion}

Rapidly deteriorating patients require prompt identification and intervention. Providing concurrent experiences using a screening tool in real-time while simultaneously providing an opportunity to practice and refine clinical judgment is essential in prelicensure nursing programs. Multiple exposures to a rapidly deteriorating patient ensure opportunities for intentional practice and a move towards metacognition. Increased metacognition results in a nursing workforce that can discern the signs and symptoms of a patient in sepsis before adverse patient events begin.

\section{CONFlicts of InTEREST Disclosure}

The authors declare that there is no conflict of interest.

\section{REFERENCES}

[1] National Center for Disease Control and Prevention [Internet]. Data and Reports, Sepsis. 2020 [cited 2020 Jun 30]. Available from: https://www.cdc.gov/sepsis/datareports/index.html
[2] Dantes RB, Epstein L. Combatting sepsis: A public health perspective. Clinical Infectious Diseases [Internet]. 2018 Sep 28 [cited 2020 Jun 30]; 67(8): 1300-2. PMid:29846544 https ://doi .org/10.1 093/cid/ciy342 
[3] Kleinpell R, Aitken L, Schorr CA. Implications of the new international sepsis guidelines for nursing care. American Journal of Critical Care. 2013; 22(3): 212-22. PMid:23635930 https: //doi.org/10.4037/ajcc2013158

[4] Makic MB, Bridges E. CE: Managing sepsis and septic shock: Current guidelines and definitions. AJN, American Journal of Nursing [Internet]. 2018 Feb [cited 2020 Jun 30]; 118(2): 34-9. PMid:29329118 https://doi.org/10.1097/01.NAJ.0000530 223.33211.f5

[5] Singer M, Deutschman CS, Seymour CW, et al. The Third International Consensus Definitions for Sepsis and Septic Shock (Sepsis3). JAMA. 2016 Feb 23; 315(8): 801. PMid:26903338 https: //doi.org/10.1001/jama.2016.0287

[6] Kalantari A, Mallemat H, Weingart SD. Sepsis definitions: The search for gold and what CMS got wrong. Western Journal of Emergency Medicine. 2017; 18(5): 951. PMid:28874949 https : //doi.org/10.5811/westjem.2017.4.32795

[7] Levy M, Evans L, Rhodes A. The surviving sepsis campaign bundle: 2018 update. Critical Care Medicine [Internet]. 2018 Jun [cited 2020 Jun 30]; 46(6): 997-1000. PMid:29767636 https: //doi.org/10.1097/CCM.0000000000003119

[8] Raines K, Berrios RAS, Guttendorf J. Sepsis education initiative targeting qSOFA screening for non-ICU patients to improve sepsis recognition and time to treatment. J Nurs Care Qual. 2019; 34(4): 318-24. PMid:30585981 https://doi .org/10.1097/NCQ. 0000 000000000379

[9] Allen G. Barriers to non-critical care nurses identifying and responding to early signs of clinical deterioration in acute care facilities. Medsurg Nurs [Internet]. 2020 Jan [cited 2020 Jun 30]; 29(1): 43-52.

[10] Harley A, Johnston A, Denny KJ, et al. Emergency nurses' knowledge and understanding of their role in recognising and responding to patients with sepsis: A qualitative study. International Emergency Nursing. 2019; 43: 106-12. PMid:30733005 https ://doi .org/10 $.1016 / j$.ienj . 2019.01.005

[11] Mau KA, Fink S, Hicks B, et al. Advanced technology leads to earlier intervention for clinical deterioration on medical/surgical units. Applied Nursing Research. 2019; 49: 1-4. PMid:31495412 https://doi.org/10.1016/j.apnr.2019.07.001

[12] Benner P, Sutphen M, Leonard V, et al. Educating nurses. A call for radical transformation. Stanford CA: Jossey-Bass; 2010. 260 p.

[13] Tanner CA. Thinking like a nurse: A research-based model of clinical judgment in nursing. J Nurs Educ. 2006; 45(6): 204-11. PMid:16780008 https ://doi .org/10.3928/01484834-20060 601-04

[14] Abe Y, Kawahara C, Yamashina A, et al. Repeated scenario simulation to improve competency in critical care: A new approach for nursing education. Am J Crit Care [Internet]. 2013 [cited 2020 Jun 30]; 22(1): 33-40. PMid:23283086 https ://doi .org/10.4037/ ajcc2013229

[15] Bogossian F, Cooper S, Cant R, et al. Undergraduate nursing students' performance in recognising and responding to sudden patient deterioration in high psychological fidelity simulated environments: An australian multi-centre study. Nurse Educ Today. 2014; 34(5): 691-6. PMid:24183634 https://doi.org/10.1016/j.nedt.2013.09 .015

[16] Choi EH, Kim EH. Effects of repeated exposure in simulation-based education on hospital emergency care. International Journal of U- and E- Service, Science and Technology [Internet]. 2016; 9(1): 277-286. https://doi.org/10.14257/ijunesst.2016.9.1.29

[17] Kaddoura M, Vandyke O, Smallwood C, et al. Perceived benefits and challenges of repeated exposure to high fidelity simulation experiences of first degree accelerated bachelor nursing stu- dents. Nurse Educ Today. 2016; 36: 298-303. PMid:26260522 https://doi.org/10.1016/j.nedt.2015.07.014

[18] Sivertsen N, McNeill L, Müller A. A redo station after debrief improves learning in undergraduate nursing simulation. Clinical Simulation in Nursing. 2016; 12(11): 469-72. https ://doi.org/10.1 016/j.ecns. 2016.07.007

[19] Tofil NM, Peterson DT, Wheeler JT, et al. Repeated versus varied case selection in pediatric resident simulation. Journal of graduate medical education [Internet]. 2014 Jun [cited 2020 Jun 30]; 6(2): 275-9. PMid:24949131 https://doi.org/10.4300/JGME-D-1 3-00099. 1

[20] Scoresby J, Shelton BE. Reflective redo from the point of error: Implications for after action review. Simulation \& Gaming. 2014; 45(4-5): 666-96. https://doi.org/10.1177/1046878114549426

[21] Chapelain P, Morineau T, Gautier C. Effects of communication on the performance of nursing students during the simulation of an emergency situation. Journal of Advanced Nursing. 2015; 71(11): 26502660. PMid:26189933 https://doi .org/10.1111/jan. 12733

[22] Institute of Medicine (US). Committee on the Robert Wood Johnson Foundation Initiative on the Future of Nursing. The future of nursing: Leading change, advancing health. National Academies Press Washington, DC; 2011

[23] Hayden J, Keegan M, Kardong-Edgren S, et al. Reliability and validity testing of the creighton competency evaluation instrument for use in the NCSBN national simulation study. Nursing Education Perspectives. 2014; 35(4): 244-52. PMid:25158419 https: //doi.org/10.5480/13-1130.1

[24] Cooper S, Kinsman I, Buykx P, et al. Managing the deteriorating patient in a simulated environment: nursing students' knowledge, skill and situation awareness. Journal of Clinical Nursing. 2010; 19(1516): 2309-2318. PMid:20659205 https://doi.org/10.1111/j. $1365-2702.2009 .03164 . x$

[25] Cooper S, Beauchamp A, Bogossian F, et al. Managing patient deterioration: a protocol for enhancing undergraduate nursing students' competence through web-based simulation and feedback techniques. BMC Nursing [Internet]. 2012 [cited 2020 Jun 30]; 11(1): 18-24. PMid:23020906 https://doi.org/10.1186/1472-6955-11-1 8

[26] Endacott R, Scholes J, Buykx P, et al. Final-year nursing students' ability to assess, detect and act on clinical cues of deterioration in a simulated environment. Journal of Advanced Nursing [Internet] 2010; 66(12): 2722-31. PMid:20735506 https ://doi .org/10.1 $111 / j .1365-2648.2010 .05417$. $\mathrm{x}$

[27] Sapiano AB, Sammut R, Trapani J. The effectiveness of virtual simulation in improving student nurses' knowledge and performance during patient deterioration: A pre and posttest design. Nurse Education Today [Internet]. 2018; 62(2018): 128-133. PMid:29335162 https://doi.org/10.1016/j.nedt.2017.12.025

[28] Scholes J, Endacott R, Biro M, et al. Clinical decision-making: Midwifery students' recognition of, and response to, post partum haemorrhage in the simulation environment. BMC pregnancy and childbirth [Internet]. 2012 Mar 23; 12(1): 1-12. PMid:22443712 https://doi.org/10.1186/1471-2393-12-19

[29] Cooper S, McConnell-Henry T, Cant R, et al. Managing deteriorating patients: Registered nurses' performance in a simulated setting. The Open Nursing Journal. 2011; 5: 120. PMid:22216077 https://doi.org/10.2174/18744346011050100120

[30] Cooper S, Porter J, Peach L. Measuring situation awareness in emergency settings: A systematic review of tools and outcomes. Open access emergency medicine: OAEM. 2014; 6: 1. PMid:27147872 https://doi.org/10.2147/OAEM.S53679 
[31] Cooper SJ, Hopmans R, Cant RP, et al. Deteriorating patients: Global reach and impact of an E-simulation program. Clin Simul Nurs [Internet]. 2017 [cited 2019 Oct 8]; 13(11): 562-72. https : //doi.org/10.1016/j.ecns.2017.06.004

[32] Abellson A, Lindwall L, Rystedt I, et al. Effect of repeated simulation on the quality of trauma care. Clinical Simulation in Nursing [Internet]. 2017 [cited 2020 Jun 30]; 13(12): 601-8. https: //doi.org/10.1016/j.ecns.2017.07.006

[33] Dzioba J, Cant R, Cooper S, et al. Barriers and enablers to learning during team-based clinical simulations: Reflective interviews with final year undergraduate nursing students. Journal of Nursing Education and Practice. 2014; 4(10): 32-9. https ://doi .org/10.543 o/jnep.v4n10p32

[34] Cant RP, Cooper SJ. Use of simulation-based learning in undergraduate nurse education: An umbrella systematic review. Nurse Educ Today. 2017; 49: 63-71. PMid:27902949 https : //doi .org/10.1 016/j.nedt.2016.11.015

[35] Seymour CW, Gesten F, Prescott HC, et al. Time to treatment and mortality during mandated emergency care for sepsis. N Engl J Med 2017; 376(23): 2235-44. PMid:28528569 https ://doi .org/10.1 056/NEJMoa1703058

[36] Drahnak DM, Hravnak M, Ren D, et al. Scripting nurse communication to improve sepsis care. Medsurg Nursing. 2016; 25(4): 233.

[37] Long D, Capan M, Mascioli S, et al. Evaluation of user-interface alert displays for clinical decision support systems for sepsis. Crit Care Nurse. 2018; 38(4): 46-54. PMid:30068720 https://doi .or $\mathrm{g} / 10.4037 / \mathrm{ccn} 2018352$

[38] O’Shaughnessy J, Grzelak M, Dontsova A, et al. Early sepsis identification. [Internet]. Jannetti Publications, Inc; 2017 [cited 2020 Jun 30]; 248 p. Available from: http://search.ebscohost. com/login. aspx?direct=t rue\&AuthType=ip, shib\&db=edsggo\&AN=edsgcl . 503466844 \&site=eds - live\&s cope=site\&custid=ken 1

[39] Proffitt RD, Hooper G. Evaluation of the (qSOFA) tool in the emergency department setting: Nurse perception and the impact on patient care. Advanced Emergency Nursing Journal. 2020; 42(1): 54-62. PMid:32000191 https://doi.org/10.1097/TME.0000000000 000281

[40] Threatt DL. Improving sepsis bundle implementation times: A nursing process improvement approach. J Nurs Care Qual. 2020; 35(2): 135-9. PMid:31290779 https://doi.org/10.1097/NCQ.0000 000000000430

[41] Dalton M, Harrison J, Malin A, et al. Factors that influence nurses' assessment of patient acuity and response to acute deterioration. British Journal of Nursing. 2018; 27(4): 212-8. PMid:29457945 https://doi.org/10.12968/bjon.2018.27.4.212
[42] Alberto L, Marshall AP, Walker R, et al. Screening for sepsis in general hospitalized patients: a systematic review. [Internet]. Elsevier B.V; 2017 [cited 2020 Jun 30]. 305 p. Available from: http://search.ebscohost.com/login.aspx?dire $c t=$ true\&AuthType $=$ ip, shib\&db=edsgao\&AN=edsgcl .498 $716547 \&$ site $=e d s-1$ ive\&s cope=site\&custid=ken1DOI : 10.1016/j.jhin.2017.05.005 PMid:28506711 https://doi.org/10.1016/j.jhin.2017.05.005

[43] Bryant SG. Collaborating to educate nursing students on sepsis recognition and response. Nurs Manage. 2019; 50(5): 46-51. PMid:31045712 https://doi.org/10.1097/01. NUMA.000055 $7622.19814 .5 \mathrm{e}$

[44] Diaz DA, Anderson M, Quelly SB, et al. Early recognition of pediatric sepsis simulation checklist-an exploratory study. J Pediatr Nurs. 2020; 50: 25-30. PMid:31675548 https ://doi.org/10.1016/j . pedn.2019.10.004

[45] McCallum J, Duffy K, Hastie E, et al. Developing nursing students' decision making skills: Are early warning scoring systems helpful? Nurse education in practice. 2013; 13(1): 1-3. PMid:23062466 https://doi.org/10.1016/j.nepr.2012.09.011

[46] Mezirow J. Transformative dimensions of adult learning. San Francisco (CA): Jossey-Bass; 1991. 247 p.

[47] Mezirow J. Transformation theory of adult learning. In: Welton M, ed. In defense of the lifeworld: critical perspectives on adult learning. New York: State University of New York Press; 1995. 272 p.

[48] Taylor EW. Transformative learning Theory In: Transformative Learning Meets Building. Brill Sense; 2017 p. 17-29. https:// doi.org/10.1007/978-94-6300-797-9_2

[49] INACSL Standards Committee. INACSL standards of best practice: SimulationSM simulation design. Clinical Simulation in Nursing. 2016; 12: S5-S12. https://doi.org/10.1016/j.ecns. 2016. 09.005

[50] Todd M, Manz JA, Hawkins KS, et al. The development of a quantitative evaluation tool for simulations in nursing education. International Journal of Nursing Education Scholarship [Internet]. 2008 Nov 25 [cited 2020 Jun 30]; 5(1): 41-17. PMid:19049492 https://doi.org/10.2202/1548-923X.1705

[51] R Core Team. R: A language and environment for statistical computing [Internet]. 2020 [cited 2020 Jun 30]. Available from: https : //www.R-project.org/

[52] SAS Institute Inc. The MIXED Procedure. SAS/STAT $®$ 14.1 User's Guide [Internet]. Cary, NC: SAS Institute Inc. 2015 [cited 2020 Jun 30]. Available from: https://support.sas.com/documentat ion/onlinedoc/stat/141/mixed.pdf 